\title{
A simple technique to insert urodynamic catheter in difficult cases
}

\author{
Nasir Mahmood, MD, FRCS(Urol) \\ Western Memorial Regional Hospital, Corner Brook, NL
}

nsertion of urodynamic catheter is quite straightforward in most cases. However, in patients with previous transurethral resection of the prostate, high bladder neck, prostatic enlargement or urethral strictures, this catheterization can be challenging and sometimes impossible. Here is a simple procedure using a flexible cystoscope to overcome this problem.

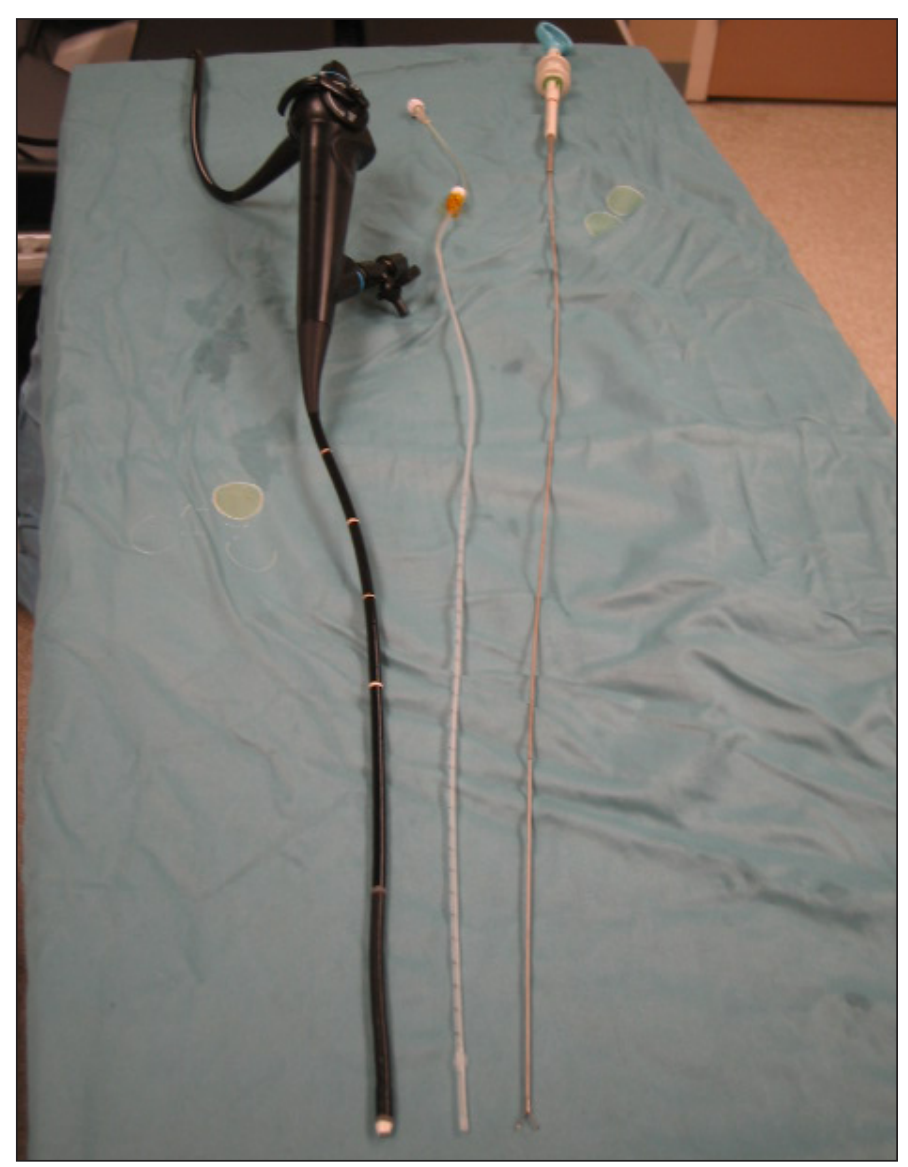

Fig. 1. Left to right: Ends of cystoscope, urodynamic catheter, grasper.
Cystometrogram, urodynamics or video-urodynamics are part of most urology units across Canada. These tests are performed in the urology suite as an outpatient procedure. The flexible cystoscopy is performed in the same suite in most places and is easily available. Occasionally, the urologist is called by the urology technician to help in difficult insertions of the urodynamics catheter. I use the flexible cystoscope and grasping forceps to overcome this problem. To my knowledge, this technique has not been previously described.

The grasping forceps is passed through the working channel of the flexible cystoscope and the tip of the urodynamic catheter is grasped with the grasping forceps (Fig. 1, Fig. 2, Fig. 3). The scope with the catheter in the grasper is then inserted in the urethra and under direct vision threaded up to the bladder. The catheter is released from the grasper, which is then removed. The cystoscope is removed while holding the urodynamic catheter so that the catheter does not slide out with the scope. This technique has been helpful in difficult cases.

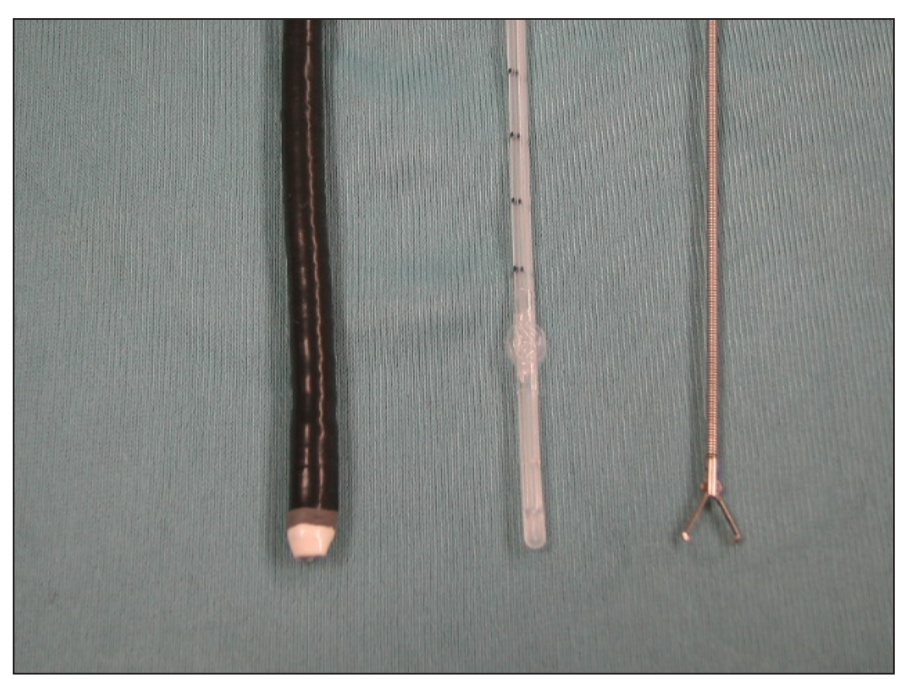

Fig. 2. Left to right: Cystoscope, urodynamic catheter, grasper. 


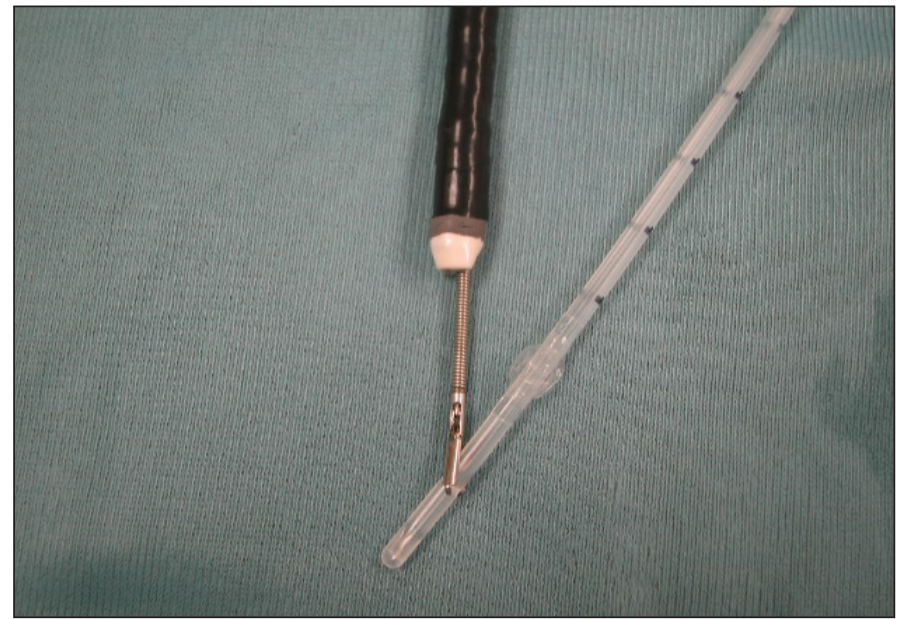

Fig. 3. Assembled instruments prior to insertion into urethra.

If difficulty is encountered during catheterization with the urodynamic catheter, a flexible cystoscope and grasper are all that is required to overcome this problem in a very simple way.
Competing interests: None declared.

This paper has been peer-reviewed.

Correspondence: Dr. Nasir Mahmood, Consultant Urologist, Western Memorial Regional Hospital, 1 Brookfied Ave., PO Box 2005, Corner Brook, NL A2H 6J7; fax: 709-639-1181; nmnasirmahmood@gmail.com 